\title{
PKM SEBAGAI BRAND RECALL UNTAR (STUDI KASUS WEBINAR SMA KRISTEN KETAPANG III BOGOR)
}

\author{
Muhammad Adi Pribadi ${ }^{1}$, Kyla Malicckha Putri Gunarso ${ }^{2}$, Rahmi Meilani $^{3}$ \\ ${ }^{1}$ Jurusan Ilmu Komunikasi, Universitas Tarumanagara Jakarta \\ Email:adip@fikom.untar.ac.id \\ 2 Jurusan Ilmu Komunikasi, Universitas Tarumanagara Jakarta \\ Email: kyla.915190003@stu.untar.ac.id \\ ${ }^{3}$ Jurusan Ilmu Komunikasi, Universitas Tarumanagara Jakarta \\ Email: rahmi.915190249@stu.untar.ac.id
}

\begin{abstract}
Community Service (PKM) is part of the duties of lecturers to provide solutions to problems that exist in the society. Lecturers need to bring students in this activity as part of supporting the Independent Learning Independent Campus (MBKM) activities so they can gain experience in applying their knowledge in society. Students activities in supporting PKM activities will add to their portfolios in preparing themselves to get a professional certificate from BNSP in the field of public relations as part of a diploma companion. PKM not only benefits the community but also benefits Tarumanagara University. The presence of Untar lecturers in PKM makes high school students aware of Untar lecturers who active role in the industry. This will make high school students know the competence of the lecturers at Untar. Therefore, it is important for lecturers to be active in PKM activities so that the Untar brand will continue to be remembered by the public so that Brand Recall will be achieved.
\end{abstract}

Keywords: Untar, PKM, MBKM

\begin{abstract}
ABSTRAK
Pengabdian Kepada Masyarakat (PKM)menjadi bagian dari tugas para dosen untuk memberikan solusi dari masalah yang ada masyarakat. Dosen perlu membawa mahasiswi/wa dalam kegiatan ini sebagai bagian dari mendukung kegiatan Merdeka Belajar Kampus Merdeka (MBKM) sehingga mahasiswi/wa bisa mendapatkan pengalaman dalam menerapkan ilmunya di masyarakat. Aktifitas mahasiswi/wa dalam mendukung kegiatan PKM akan menambah portofolio mereka dalam mempersiapkan diri untuk mendapatkan sertifikat profesi dari BNSP dalam bidang PR sebagai bagian dari pendamping ijasah. PKM tidak hanya memberikan manfaat bagi masyarakat tapi memberikan manfaat juga bagi Universitas Tarumanagara. Kehadiran para dosen Untar dalam PKM membuat murid SMA mengetahui para dosen Untar yang juga berperan aktif di Industri. Hal ini akan membuat murid SMA mengetahui kompetensi para dosen yang ada di Untar. Oleh karenanya, Penting sekali bagi Para dosen Untuk aktif dalam kegiatan PKM sehingga merek Untar akan terus diingat oleh masyarakat sehingga Brand Recall akan tercapai.
\end{abstract}

Kata kunci: Untar, PKM, MBKM

\section{PENDAHULUAN}

\section{Analisis situasi}

Universitas Tarumanagara (Untar) sebagai Universitas ternama di Indonesia perlu dijaga nama baik dan keberadaannya dengan terus mengkomunikasikan mereknya kepada masyarakat. Merek ternama bisa dilupakan oleh masyarakat apabila tidak dijaga keberadaannya karena masyarakat selalu menghadapi berbagai ragam informasi yang mampu membuat masyarakat lupa dengan merek yang dikenalnya (Kotler dan Keller: 2012). Oleh karenanya, Penting bagi Untar untuk menjaga keberadaan mereknya di masyarakat.

Untar terus menjalin komunikasi dengan masyarakat dengan menggunakan saluran komunikasi dengan memanfaatkan media konvensional dan digital. Untar telah melakukan komunikasi dengan menggunakan media televisi, radio dan cetak dalam periklanan. Komunikasi terus berlanjut keranah digital seperti website dan media sosial

Bahkan Rektor Untar, Prof Agustinus Purna Irawan, ikut terlibat secara langsung dalam kegiatan public relations dengan masyarakat. Beliau menjalin komunikasi dengan masyarakat dengan menggandeng Radio Republik Indonesia (RRI). Beliau memperlihatkan Untar kepada 
Kemenristek Dikti melalui kepemimpinan yang berprestasi sehingga beliau memperoleh penghargaan sebagai pemimpin berprestasi dari Kemenristek Dikti.

Untar sudah dikenal dikalangan pemerintah. Pada dies natalis yang ke 62, Untar mendapatkan ucapan selamat dari Presiden Republik Indonesia, beberapa Menteri, Panglima TNI dan Kapolri. Hal ini menunjukkan bahwa Untar dikenal oleh berbagai kalangan yang ada di masyarakat .

Para dosen dan tim marketing Untar perlu terus menjaga komunikasi dengan masyarakat agar keberadaan Untar tetap diketahui dan dirasakan oleh masyarakat karena produk yang dihasilkan oleh dosen dan mahasiswa mahasiswi dalam bentuk hasil riset yang terpublikasi membantu masyarakan dalam mendukung kegiatannya. Salah satu kegiatan dosen dalam memperkenalkan Untar melalui kegiatan PKM (Pengabdian Kepada Masyarakat) dimana para dosen beserta mahasiswi dan mahasiswa berperan aktif dalam memberikan solusi dari masalah yang dihadapi masyarakat.

Tim PKM dari Fikom Untar yang terdiri dari Dosen dan dua mahasiswi dari Fikom Untar menyelenggarakan webinar untuk menjadi pengusaha sejak dibangku SMA (Sekolah Menengah Atas). Kegiatan webinar dilaksanakan pada tanggal 10 september 2021 di SMA Kristen Ketapang 3 Bogor. Kegiatan PKM tidak hanya memperkenalkan Untar kepada SMA Kristen Ketapang 3 Bogor tetapi kehadiran tim memberikan informasi kepada siswa dan siswi untuk melakukan kegiatan bisnis sejak sekarang.

Tujuan komunikasi pemasaran terdapat pada brand awareness, yang terbagi menjadi brand recognition dan brand recall (Belch \& Belch: 2012; Biagi: 2005; Caemmerer; 2009; Gregory: 2004; Keller: 2008; Kotler dan Keller, Lane: 2012; Kline: 2009; Percy \& Elliot: 2012; Pribadi, Suganda, Venus dan Siswanto: 2018; Watono \& Watono: 2012). Brand recognition adalah pengetahuan konsumen terkait merek yang masih kurang sehingga mereka perlu waktu untuk mengingat merek tersebut. Misalnya ketika konsumen baru melihat iklan di televisi dari produk merek baru maka jarang sekali diantara mereka yang langsug mengingat merek dan produknya secara langsung.

Brand recall adalah kondisi dimana konsumen telah mengenal keberadaan merek dan menggunakan produknya. Misalnya, ketika konsumen merasa haus, ia langsung terfikir Aqua. Kondisi ini menunjukkan konsumen tidak hanya mengenal produk tapi ia telah mengaitkan kebutuhannya dengan merek (Belch \& Belch: 2012; Biagi: 2005; Caemmerer; 2009; Gregory: 2004; Keller: 2008; Kotler dan Keller, Lane: 2012; Kline: 2009; Percy \& Elliot: 2012; Pribadi, Suganda, Venus dan Siswanto: 2018; Watono \& watono: 2012). .

Menurut penulis, Untar sudah dikenal oleh masyarakat walaupun dari sisi program studinya memang perlu pendekatan tersendiri dari masing-masing dosen untuk melakukannya dalam bentuk pengabdian kepada masyarakat agar mereka mengetahui kualitas masing-masing program studi. fakultas ekonomi menjadi program studi yang sudah banyak dikenal oleh masyarakat karena keberadaan fakultas ekonomi di Untar dan universitas lainnya sudah sangat dikenal oleh publik. Namun fakultas ilmu komunikasi memang belum banyak orang tua dan calon mahasiswi/wa yang mengetahuinya mengingat keberadaanya yang masih belum selama fakultas ekonomi.

Disini peran dari dosen di Fakultas ilmu komunikasi untuk memperkenalkan peluang usaha dan lapangan pekerjaaan bagi para lulusannya, kepada siswa dan siswi melalui PKM. Para dosen bisa menjelaskan lebih baik terkait dengan kualitas para dosennya dimana dosen ilmu komunikasi banyak yang berperan aktif sebagai praktisi di industri komunikasi sehingga para siswa/wi SMA teryakinkan bahwa yang diajarkan oleh para dosen sesuai dengan kondisi yang ada dilapangan pekerjaan.

PKM digunakan untuk menjelaskan tentang situasi industri komunikasi melalui webinar yang ada saat ini berdasarkan pengalaman para dosen ilmu komunikasi yang juga bekerja pada 
industri. PKM akan membantu para siswa/wi untuk berubah menjadi aktif dengan menggunakan peluang yang ada di era digital dengan menjadi pengusaha.

\section{Permasalahan mitra}

SMA Kristen Ketapang 3 Bogor menjadi tempat dalam kegiatan webinar karena para guru dari SMA tersebut memerlukan para dosen yang bisa memberikan pencerahan kepada siswa dan siswi terkait kewirausahaan. Mereka perlu disadarkan bahwa menjadi pengusaha sukses tidak harus menunggu lulus SMA karena pada kenyataannya terdapat anak SD di Amerika Serikat yang sudah menjadi milyuner. Mereka juga perlu mengetahui bahwa menjadi pengusaha akan membantu negara dalam meningkatkan perekonomian Indonesia sehingga keberadaan pengusaha sangat dibutuhkan untuk meningkatkan pendapatan negara serta mengurangi pengangguran.

SMA Kristen Ketapang 3 Bogor telah mengirimkan proposal bantuan kepada Untar untuk mengirimkan dosennya dalam mengisi kegiatan webinar terkait kewirausahaan. Untar kemudian memberikan informasi kepada Dr Muhammad Adi Pribadi untuk menyiapkan materi terkait kewirausahaan. Sebagai ketua Tim, topik kewirausahaan di era digital dimana siswa dan siswi berperan penting dalam kegiatan ini menjadi topik bahasan yang dapat menarik perhatian audien di SMA tersebut.

\section{Solusi permasalahan}

Topik kewirausahaan dipilih oleh ketua tim karena SMA Kristen Ketapang membutuhkan dosen untuk membawakan tema tersebut. Disisi lain, topik ini akan membantu siswa/wi dalam mengarahkan mereka dalam mencari peluang bisnis. Pengalaman mereka yang terbatas akan dibantu oleh dosen dari Fikom Untar untuk menjelaskannya. Dimana ketua tim adalah seorang dosen, pengusaha dan asesor dari BNSP sehingga ia bisa memberikan gambaran umum terkait cara menjadi pengusaha di era digital.

STRATECOMMS adalah bisnis dengan pemanfaatan secara penuh fasilitas digital dalam menjalani kegiatan operasional bisnisnya. Produk yang dihasilkannya adalah persiapan uji kompetensi public relations dari Lembaga Sertifikasi Profesi Public Relations Indonesia (LSP PRI) - Badan Nasional Sertifikasi Profesi (BNSP) bagi calon peserta uji kompetensi. Proses pelatihan dilakukan secara online dengan menggunakan MS TEAMS dan ZOOM. Aktifitas komunikasi pemasaran yang dilakukan juga menggunakan media sosial dan media digital lainnya.

Kegiatan bisnis yang dipimpin Dr Muhammad Adi Pribadi, selaku narasumber, berhasil meraup keuntungan kurang dari setahun dalam kegiatan operasionalnya. Informasi ini yang akan diceritakan kepada siswa/wi di SMA Kristen Ketapang III Bogor. Harapan dari hasil kegiatan Webinar mampu mendorong siswa dan siswi untuk mencoba menggeluti dunia usaha sejak dini dan membuat Untar lebih dikenal oleh siswa/wi

\section{METODE PELAKSANAAN PKM}

\section{Tahapan /langkah-langkah solusi bidang kewirausahaan dan komunikasi pemasaran}

Tahapan kegiatan webinar diawali oleh ketua PKM dengan menghubungi tim marketing Universitas Tarumanagara Untuk mengetahui program yang dibutuhkan oleh tim marketing dalam pendekatan dengan siswa dan siswi SMA. Tim Marketing adalah tim yang paling kreatif dalam melakukan komunikasi dengan SMA yang ada di Indonesia untuk mempekenalkan Untar.

Tim Marketing Untar memerlukan kegiatan webinar yang bisa digunakan sebagai bagian dari kegiatan marketing Untar sekaligus memberikan kontribusi bagi negara dengan memberikan inspirasi bagi siswa dan siswi SMA untuk memulai kegiatan usaha sejak dini. Ketua tim melihat 
ide dan semangat dari tim marketing Untar untuk memperkenalkan Untar pada siswa-siswi SMA dan upaya mendorong mereka untuk menjadi pengusaha.

Tim Marketing Untar menyarankan ketua tim untuk melakukan kegiatan Webinar di SMA Ketapang III Bogor. Ketua Tim langusng mengambil kesempatan tersebut tanpa berfikir Panjang lagi karena ini adalah kegiatan yang luar biasa dalam memperkenalkan Untar dan Fikom untar menjadi lebih baik lagi. Selama ini, siswa/wi SMA hanya mengenal bagian luar dari Untar, melalui webinar, mereka akan mengenal Untar dan fikom Untar dari perspektif kualitas pengajar.

Ketua tim mengajak dua mahasiswi fikom Untar untuk mendapatkan pengalaman kegiatan diluar kampus. Mereka akan menerapkan hasil belajar mereka dalam menjadi seorang Master of Ceremony (MC) dan Moderator. Kegiatan ini tidak hanya penting untuk mereka dalam menerapkan hasil belajar tetapi Ketua tim ingin mereka mendapatkan pengalaman dan surat tugas yang nantinya bisa digunakan oleh mereka dalam mengikuti uji kompetensi Public Relations dari Badan Nasional Sertifikasi Profesi.

Ketua tim memiliki pengalaman sebagai asesor di LSPPRI-BNSP sehingga beliau mengetahui bagian-bagian unit kompetensi PR yang diperlukan oleh para mahasiswi komunikasi. Kedua mahasiswi ini sengaja diajak oleh ketua tim agar mereka bisa mempersiapkan diri untuk mengikuti uji sertifikasi profesi yang menjadi amanat dari Kemenristek-Dikbud dimana para lulusan perlu mendapatkan sertifikat profesi dari BNSP sebagai sertifikat pendukung ijazah. Untar memang mendukung kegiatan ini dengan mendorong para dosen agar mengajak mahasiswi/wa untuk berperan aktif dalam kegiatan PKM sebagai bagian dari kegiatan Merdeka Belajar Kampus Merdeka (MBKM).

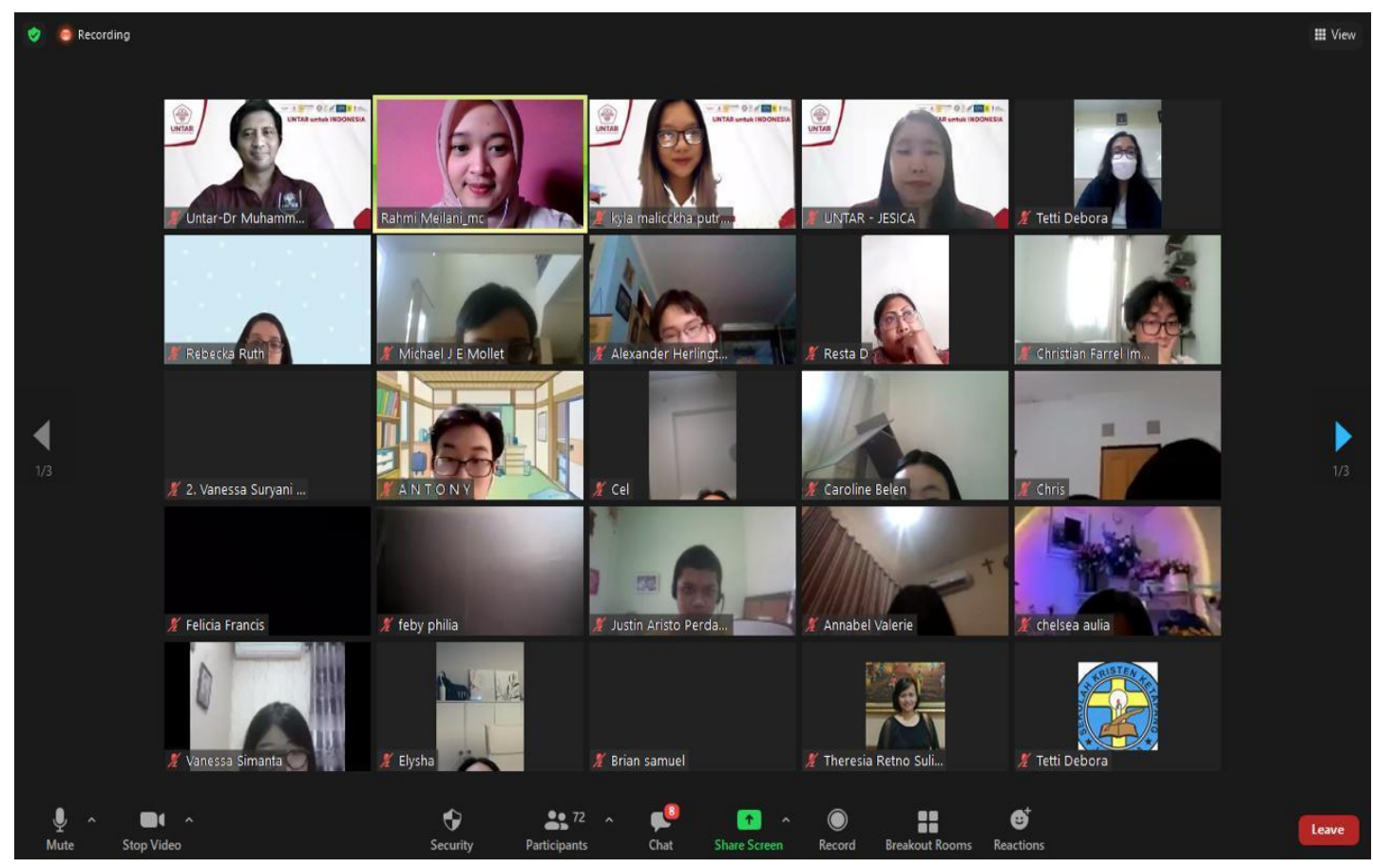

Gambar 1

MC yang juga mahasiswi Fikom Untar sedang mengawal kegiatan webinar 
Tema yang diangkat dan disetujui oleh pihak Untar dan SMA Kristen Ketapang 3 Bogor adalah "Kewirausahaan di Era Digital Untuk Siswa Siswi SMA. Poster digital telah dipersiapkan oleh Untar untuk kelancaran kegiatan ini. Gambar 1 adalah contoh poster digital yang dipersiapkan oleh Untar dalam mempublikasikan kegiatan di SMA Kristen Ketapang 3 Bogor.

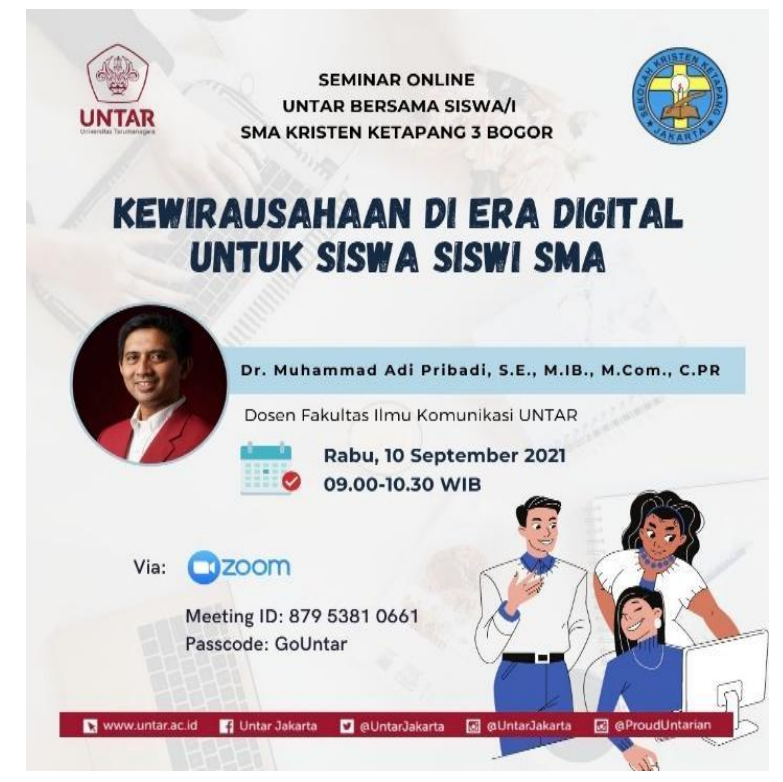

Gambar 2. Poster digital untuk kegiatan webinar

Narasumber adalah ketua tim PKM dengan membawa tema "Kewirausahaan di Era Digital Untuk Centennial". Kata Centennial dipilih dalam judul untuk memperkenalkan kepada para siswa dan siswi bahwa mereka adalah bagian dari generasi Centennial. Kata centennial dipergunakan oleh ketua tim dalam tema, untuk menarik perhatian siswa siswi untuk hadir dalam kegiatan webinar. Young (2017) menjelaskan bahwa Ogilvy selaku perusahaan periklanan membuat pengelompokkan Centennial untuk menggambarkan prilaku masyarakat di kisaran umur 17 tahun kebawah.

Ketua tim selaku narasumber menjelaskan pada siswa dan siswi dalam tiga tahap. Tahap pertama narasumber memperlihatkan pengalaman bisnis, menjadi dosen, dan aktifitasnya di Industri. Maksud dan tujuannya adalah membuat peserta webinar tahu kompetensi narasumber dan dosen Untar sehingga para peserta menyadari bahwa dosen-dosen di Untar selain aktif mengajar dan meneliti ternyata punya kegiatan bisnis dan profesi di perusahaan di perusahaan lain. Hal ini akan menyadarkan mereka bahwa dosen Untar adalah seorang praktisi yang nantinya akan memberikan contoh teori yang dikaitkan dengan kondisi yang ada di Industri sehingga jurang pemisah antara dunia pendidikan dan industri semakin kecil. Logika ini disampaikan oleh narasumber kepada calon-calon mahasiswi/wa Untar dimasa mendatang agar mereka memilih Untar sebagai tempat untuk menuntut ilmu.

Tahap kedua adalah pembicara menjelaskan hebatnya menjadi pengusaha dibandingkan pekerja karena seorang pengusaha tidak hanya membantu konsumen mendapatkan produknya tetapi pengusaha ikut membantu negara dalam mengurangi pengangguran serta ikut membantu masyarakat dalam memperoleh kesejahteraan yang lebih baik. Pesan ini disampaikan agar para 
peserta tersadar kehebatan yang dimiliki oleh seorang pengusaha dimata masyarakat dan negara. Contoh yang diberikan adalah pendiri Google yang menyerap ribuan pekerja di negaranya dan negara lainnya.

Tahap ketiga adalah narasumber memberikan cara kepada peserta webinar, menjadi pengusaha sukses di era digital dengan menerapkan model perencanaan komunikasi pemasaran. Model ini adalah hasil dari penelitian ketua tim PKM saat menempuh program doktor. Model ini cocok untuk diterapkan kepada startup business karena tahapannya terkoordinasi dan terukur sehingga memudahkan bagi para penggunanya.

\section{Partisipasi mitra dalam kegiatan PKM}

Mitra PKM adalah para guru SMA Kristen Ketapang 3 Bogor, yang ditugaskan untuk menjadi panitia. Mereka mempersiapkan zoom dan youtube agar kegiatan webinar bisa terpublikasi di SMA dan masyarakat. Mereka juga berperan dalam mengatur jadwal webinar dan peserta agar pelaksanaan kegiatan dapat berjalan dengan lancar.

\section{Uraian kepakaran dan tugas masing-masing anggota tim}

Dr Muhammad Adi Pribadi, S.E., M.IB., M.Com., C.PR adalah salah satu dosen dari Fakultas ilmu komunikasi. Pendidikan terakhir yang ditempuhnya adalah program doktor. Beliau memiliki sertifikat profesi Public Relations dan Asesor dari Badan Nasional Sertifikasi Profesi, selain memiliki sertifikat dosen. Aktifitas diluar kampus adalah sebagai asesor di LSP PRI BNSP dan Direktur STRATECOMMS

Kyla Malicckha Putri Gunarso (915190003) adalah mahasiswi semester lima dari Fakultas ilmu komunikasi. Saat ini, Kyla aktif diorganisasi kemahasiswaan seperti Dewan Perwakilan Mahasiswa Fakultas Ilmu Komunikasi (DPM Fikom Untar) dan Public Relations Organization Fakultas Ilmu Komunikasi (PRO Fikom Untar)

Rahmi Meilani 915190249 adalah mahasisiwi dari Fakultas Ilmu Komunikasi Universitas Tarumanagara. Saat ini, ia aktif pada kegiatan kemahasiswaan seperti Public Relation Organization Fakultas Ilmu Komunikasi ( PRO Fikom Untar )

\section{HASIL DAN PEMBAHASAN}

\section{Hasil}

Keberadaan Tim PKM Untar di SMA Kristen Ketapang 3 Bogor memberikan manfaat bagi Siswi/wa SMA dan Untar. Bagi Siswa/wi, mereka mendapatkan informasi cara menjadi pengusaha sejak SMA. Merekat mendapatkan teori dan aplikasi dalam kegiatan bisnis. Karena Narasumber adalah seorang praktisi bisnis dan dosen, ia mampu mengkaitkan antara teori dan aplikasinya. Konsep perencanaan komunikasi pemasaran yang dijelaskan kepada mereka adalah hasil penelitian disertasi narasumber yang teraplikasi dalam kegiatan bisnisnya saat ini. Hal ini memudahkan bagi para siswa/wi belajar menjadi pengusaha, dari studi kasus yang nyata.

Keuntungan bagi untar adalah reputasi Untar terlihat dari kompetensi narasumbernya yang berpendidikan doktor, memiliki sertifikasi dosen, sertifikasi profesi dari BNSP dan pengusaha karena Narasumber menjelaskan kompetensi dirinya saat memperkenalkan diri kepada siswa/wi agar mereka mengetahui kompetensi yang dimiliki salah satu dosen di Universitas Tarumanagara. 


\section{Pembahasan}

Tim PKM Untar telah melakukan Recall merek selama proses PKM. Hal ini tergambarkan dengan memberikan penjelasan terkait kompetensinya saat melakukan presentasi kepada siswa/wi SMA Kristen Ketapang 3 Bogor sehingga mereka yang lupa akan keberadaan Untar, mereka akan teringat kembali dengan Untar. Hal ini sejalan dengan teori Recalling, bahwa brand akan terus teringat oleh target khalaknya ketika mereka selalu diingatkan. Walaupun merek sudah terkenal, namun merek bisa terlupakan konsumen jika tidak pernah diingatkan oleh pemilik merek (Keller, 2008)

\section{KESIMPULAN DAN SARAN}

PKM yang melibatkan dosen dan mahasiswi/wa akan memberikan manfaat buat masyarakat dan Untar. Bagi masyarakat, Para dosen dan mahasiswa/wi memberikan solusi yang menjadi masalah yang ada di masyarakat. Manfaat bagi Untar adalah masyarakat mengetahui kompetensi yang dimiliki oleh para dosen di Untar yang memiliki sepak terjang di industri, selain menjadi peneliti dan pengajar, sehingga mereka bisa memberikan gambaran umum terkait hubungan antara teori dengan aplikasinya di lapangannya. Hal seperti ini ingin didengar oleh siswa/wi SMA karena mereka ingin lulus kuliah yang kemudian diterima industri.

\section{Ucapan Terima Kasih}

Tim PKM ingin mengucapkan Terima kasih atas bantuan dari Universitas Tarumanagara yang selalu memberikan dukungan penuh dalam bentuk moril dan pendanaan pada kegiatan dosen dan mahasiswi/wa di masyarakat dalam upaya untuk mendukung kegiatan Merdeka Belajar Kampus Merdek (MBKM). Hal ini akan memberikan pengalaman positif bagi dosen dan mahasiswi saat menyumbangkan pengetahuan dan kemampuan mereka di masyarakat.

\section{REFERENSI}

Belch, George E. \& Belch, Michael A. 2012. Advertising and Promotion: An Integrated Marketing Communication Perspective. Singapore: McGraw-Hill.

Biagi, Shirley. 2005. Media Impact. Sacramento: Thompson-Wadsworth

Gregory, Anne. 2004. Planning and Managing Public Relations Campaigns: A Strategic Approach. Kogan Page Limited. Great Britain

Keller, Kevin Lane. (2008). Strategic Brand Management: Building, Measuring, and Managing Brand Equity. USA:Pearson Prentice Hall

Kotler, Philip. \&Keller, Kevin Lane. 2012. Marketing Management. United States of America: Pearson.

Kline, Stephen. 2009. Ronald's New Dance: A Case Study Of Corporate Re-Branding In The Age Of Integrated Marketing Communication. Dalam The Advertising Handbook. USA dan Kanada: Routledge.

Percy, Larry., Elliot, Richard Rossenbaum. 2012. Strategic Advertising Management. Great Britain : Oxford University Press.

Pribadi, Muhammad Adi., Suganda, Dadang., Venus, Anter., Susanto, Eko Harry. (2018). Dinamika Perkembangan Perusahaan Periklanan Indonesia. Disertasi. Jatinangor, Indonesia: Universitas Padjadajaran

Watono, A Adji., Watono, Maya C. 2012. IMC that Sells: Bring Your Brand to the Top with Indonesian Style Communication. Jakarta: PT Gramedia 
Young, Miles. (2017). (gilvy On Advertising: In the Digital Age". New York, USA: BLOOMSBURY 